\title{
COVID-19 Pandemic and its Impact on Pharmacy Education
}

\section{COVID-19 Pandemisi ve Eczacllık Eğitimine Etkisi}

\author{
(D) Kanwal $A S H I Q^{1 *}$, (D) Mayyda Asif BAJWA1, (D) Sana ASHIQ² \\ 1Superior University, Faculty of Pharmaceutical Sciences the Superior College, Lahore, Pakistan \\ 2University of the Punjab, Centre for Applied Molecular Biology (CAMB), Lahore, Pakistan
}

Key words: Pharmacy, COVID-19, education

Anahtar kelimeler: Eczane, COVID-19, eğitim

\section{Dear Editor,}

The sudden occurrence of Coronavirus Disease-2019 (COVID-19) reached a pandemic state soon after its global emergence in the early spring of the year 2020. It was immediately followed by a worldwide shutdown and the practice of social distancing. In this unprecedented situation, encompassing day-to-day work and employment, all sorts of activities faced interruption in the worst possible way, like never before. Lockdown turned into a significant and unforeseen challenge of the year 2020 for allparticularly the management and administration of workplaces and educational institutes. To ensure means of earning degrees and evade their delay, immediate policies and strategies were implemented. It was mandatory following the government announcement that education must be continued without interruption. Under such circumstances, digital learning emerged and was adopted by all institutes worldwide to ensure continued instruction. This brought forth a sudden shift from traditional on-campus classes to e-classes. Students were kept busy, and any delay was avoided; on the other hand, a panic was initiated among teachers, students, and their families. However, within a short time, teachers across the globe were delivering lectures virtually while students were participating online.

In addition to this, pre-scheduled scientific meetings, workshops, and educational conferences were delayed or canceled, considering universities and private halls' shutdown.
The gathering was also devalued, with people allowed to interact only at a safe distance of 6 feet, hindering the exchange of knowledge and information. Keeping the severity of the situation in mind, some essential shifts were the need of the hour and the way forward to combat interruptions. Many organizers successfully switched to virtual events, managed to adhere to the original event schedule, transmitting due information quickly without any added delay, and welcomed a larger community. However, the other side of the picture hides some limitations besides the aforementioned tools and technologies, lending help in the crisis. Besides the support rendered, unobstructed network access, online interruptions, and voice modulations remained some of the technical flaws, other than the absence of emotional connection and real-time simulation still being in question. ${ }^{2}$

It is important to note that our current concerns and observations come from online sessions conducted with the Doctor of Pharmacy (Pharm-D) program, a professional degree instituted on a multidisciplinary curriculum. This course of study entails a series of theoretical sessions, combined with practical demonstrations and exercises. The respective regulatory council binds pharmacy aspirants to reach further afield, such as hospitals, clinics, and industries, and gain realtime experience to strengthen their understanding and bring their skills into practice. In compliance with the same, pharmacy

\footnotetext{
*Correspondence: kanwal.ashiq@superior.edu.pk, Phone: 04235330361, ORCID-ID: orcid.org/0000-0001-8193-5147

Received: 24.09.2020, Accepted: 12.10.2020

๑Turk J Pharm Sci, Published by Galenos Publishing House.
} 
students undertake regular laboratory work, internships, and graded field visits, back-to-back during the degree's five-year span. $^{3}$

Besides the scientific and clinical core of the profession, hands-on clinical experience and onsite experimental learning in clinical settings were impeded. Thus, the very first challenge dealt with the suspension of on-campus classes was the adjustment of curricula according to the current needs and choices available. Various platforms were brought into use, such as the Learning Management System, Google Meet, Zoom, etc., as conventional platforms such as Skype and Viber failed to cope with the current crisis. Many senior teachers and nontechnical people in pharmacy viewed this as a challenge yet successfully adapted to the changes. The situation was no different for students; while many were quick to learn, those in remote and rural areas were stuck with inadequate computer and internet facilities. Hence, a solution was provided via recorded lectures followed by open-book tests and quizzes to establish sound feedback system. ${ }^{4}$

The pandemic effect on students in health fields such as Pharm-D was manifested in grave consequences comprising the loss of clinical rotations, laboratory demonstrations, industrial internships, and other clerkships. Keeping this in mind, it was essential to provide a suitable alternative and cater to this professional degree's practical needs, as the role of pharmacists in community and hospital settings is critical in any healthcare system. In response to this, e-learning strategies covered the practical needs of the scientific curriculum well, and simulations of laboratory settings were prepared thoroughly and taken up at whatever level possible to confirm the delivery of practical skills. Although the closure of institutes did not impede lecture delivery, and examinations were still administered in earnest. However, upon completion of pharmacy curriculum uniformity in understanding, failed across boards. Many competitive examinations, along with board examinations, were canceled on the national and international levels, and scholarships were withheld or abandoned altogether. Having mentioned the issues and proposed solutions, the professionals graduating this year shall face consequences of the COVID-19 pandemic. Besides the educational interruptions they have faced, they shall be interviewed on strict grounds to assess their knowledge only if they have bypassed the residual effects of the pandemic, such as a major global recession.,

To conclude, COVID-19, which has acutely disrupted the entire learning process, has also raised concerns regarding pharmacy education and other fields in general. Students from different field have different needs, yet for pharmacy students, practical knowledge is as essential as theory. Despite all efforts made, a significant gap remains, demanding some initiative or policy to provide pharmacy students with hands-on clinical training, industrial exposure, hospital rounds, and retail residencies to stir the required level of confidence before entering professional life.

Conflicts of interest: No conflict of interest was declared by the authors. The authors alone are responsible for the content and writing of the paper.

\section{REFERENCES}

1. Bao W. COVID-19 and online teaching in higher education: a case study of Peking University. Hum Behav Emerg Technol. 2020;2:113-115.

2. Almarzooq Z, Lopes M, Kochar A. Virtual learning during the COVID-19 pandemic: a disruptive technology in graduate medical education. J Am Coll Cardiol. 2020;75:2635-2638.

3. Scahill SL, Atif M, Babar ZU. Defining pharmacy and its practice: a conceptual model for an international audience. Integr Pharm Res Pract. 2017;6:121-129.

4. Sandars J, Correia R, Dankbaar M, de Jong P, Goh PS, Hege I, Masters K, Oh SY, Patel R, Premkumar K, Webb A, Pusic M. Twelve tips for rapidly migrating to online learning during the COVID-19 pandemic. Med Ed Publish. 2020;9:1-14.

5. Chan AH, Rutter V, Ashiru-Oredope D, Tuck C, Babar ZU. Together we unite: the role of the Commonwealth in achieving universal health coverage through pharmaceutical care amidst the COVID-19 pandemic. J Pharm Policy Pract. 2020;13:1-7.

6. Bala L, van der Vleuten C, Freeman A, Torre D, Heeneman S, Sam AH. COVID-19 and programmatic assessment. Clin Teach. 2020;17:420-422. 